\section{Commentary: Blowing stuff up: Balloon fracture fenestration with thoracic endovascular aortic repair for chronic type $B$ aortic dissection}

\author{
George J. Arnaoutakis, MD, ${ }^{\mathrm{a}}$ and \\ Ibrahim Sultan, MD ${ }^{\mathrm{b}, \mathrm{c}}$
}

Thoracic endovascular aortic repair (TEVAR) has been increasingly used in patients with chronic type B aortic dissection. However, aortic remodeling in chronic type B aortic dissection has not been as positive compared with what is seen with aneurysmal disease or with acute type B aortic dissection. Levack and colleagues ${ }^{1}$ from Cleveland report their single-center experience using endovascular balloon fracture fenestration (BFF) to promote positive aortic remodeling during treatment of chronic type B aortic dissection. TEVAR endograft placement was followed by adjunctive BFF to achieve stent graft apposition to the adventitia of the thoracic aorta. The technique reported in this article is a slight variation from the original "Knickerbocker" technique described by Kolbel and colleagues ${ }^{2}$ in 2014. The current study details implant of commercially available endografts followed by balloon expansion of the device along the majority of aortic coverage versus the midsection alone, which represents the major difference from the original "Knickerbocker" procedure. The concept of these techniques centers on achieving obliteration of false lumen flow and true lumen expansion, with the ultimate goal being positive aortic remodeling. Definitions of positive aortic remodeling have varied in the past; however, the recent consensus document on type $\mathrm{B}$ aortic dissection should provide additional clarity on this definition for future studies.

\footnotetext{
From the ${ }^{a}$ Division of Cardiovascular Surgery, University of Florida Health, University of Florida College of Medicine, Gainesville, Fla; and ${ }^{\mathrm{b}}$ Division of Cardiac Surgery, Department of Cardiothoracic Surgery, University of Pittsburgh and ${ }^{\mathrm{c}} \mathrm{Heart}$ and Vascular Institute, University of Pittsburgh Medical Center, Pittsburgh, Pa.

Disclosures: I.S. receives institutional research support from Medtronic and AtriCure. G.J.A. reported no conflicts of interest.

The Journal policy requires editors and reviewers to disclose conflicts of interest and to decline handling or reviewing manuscripts for which they may have a conflict of interest. The editors and reviewers of this article have no conflicts of interest.

Received for publication Oct 5, 2020; revisions received Oct 5, 2020; accepted for publication Oct 6, 2020; available ahead of print Oct 13, 2020.

Address for reprints: Ibrahim Sultan, MD, Division of Cardiac Surgery, Department of Cardiothoracic Surgery, University of Pittsburgh, Center for Thoracic Aortic Disease, Heart and Vascular Institute, University of Pittsburgh Medical Center, 5200 Centre Ave, Suite 715, Pittsburgh, PA 15232 (E-mail: sultani@upmc.edu). J Thorac Cardiovasc Surg 2022;164:11-2 $0022-5223 / \$ 36.00$

Copyright (c) 2020 by The American Association for Thoracic Surgery https://doi.org/10.1016/j.jtcvs.2020.10.018
}

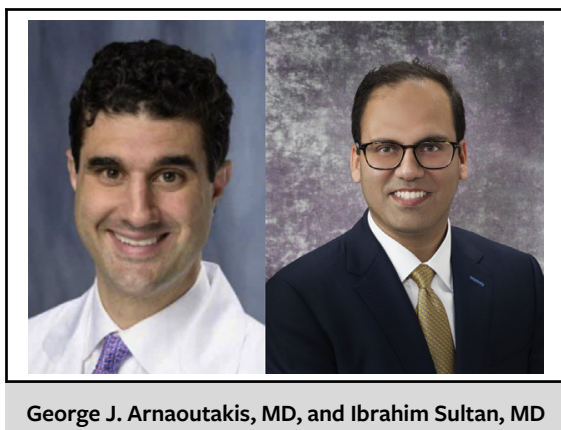

CENTRAL MESSAGE

TEVAR followed by balloon fracture fenestration (BFF) is a safe and potentially effective technique to achieve true lumen apposition to the adventitia and promote aortic remodeling.

As the authors mention in their introduction, and a point we believe merits emphasis, the conventional open surgical repair for patients with chronic type B dissection harbors significant risk of morbidity and mortality, as well as prolonged recovery even in the absence of postoperative complications. Hence, endovascular techniques to treat chronic type B dissection with aneurysmal degeneration have been pursued, and there are risk models to predict outcomes after TEVAR ${ }^{4}$ However, achieving positive aortic remodeling in a large proportion of patients has proved challenging, largely related to the presence of distal fenestrations that are often present in the chronic phase of this disease. ${ }^{5,6}$ While the technique of ballooning an endograft in the setting of chronic type B dissection to achieve favorable remodeling has been adopted in many centers, including our own, there are scant data on short and mid-term outcomes with this procedure. Therefore, the data provided by the 49 patients published in this study are a welcome addition to the existing literature on this technique.

These data support the safety of this procedure, as there was only one instance of postoperative mortality in a patient who underwent emergency type A repair followed by TEVAR and BFF complicated by visceral malperfusion. There were no instances of aortic rupture related to ballooning. There were 3 presumed cases of stent-induced new entry tear, requiring distal intervention due to compromised visceral perfusion. In their later experience, the authors avoided ballooning in the region of the distal most stent of the endograft and have seen no further instances of this phenomenon. The occurrence of stent-induced 
new entry during TEVAR deployment can cause rapid changes in true lumen flow and pressurization and reinforces the complex nature of these endovascular procedures. While a rare occurrence in this series, it also highlights the utility of intravascular ultrasound and adjunctive procedures such as bare stent extension into the visceral segment and potential need for visceral branch stenting.

In addition, this study lends support to the potential effectiveness of promoting aortic remodeling with this technique, as the authors observed a $74 \%$ rate of false lumen thrombosis but only $26 \%$ satisfying their definition of positive aortic remodeling. However, they used a slightly more stringent definition for positive aortic remodeling, defined as (1) false lumen thrombosis; AND (2) decrease in aortic dimension by $10 \%$ or greater; AND (3) increase in true lumen area by at least $10 \%$. As the authors and others accumulate more experience with these procedures, it will be interesting to see if studies with more patients and longer follow-up corroborate the very encouraging findings reported in this study.

The treatment of aneurysmal degeneration from chronic type $\mathrm{B}$ dissection remains a clinical challenge. It is incumbent on cardiovascular surgeons to embrace innovation and be early adopters of these new treatment paradigms for this pathology. Long-term follow-up and prospective data are necessary to fully understand the impact of this treatment strategy. How the application of branched or fenestrated endovascular technology to the visceral aortic segment in combination with the TEVAR and BFF technique remains to be seen.

\section{References}

1. Levack MM, Kindzelski BA, Miletic KG, Vargo P, Bakaeen FG, Johnston DR, et al. Adjunctive endovascular balloon fracture fenestration for chronic aortic dissection. J Thorac Cardiovac Surg. 2022;164:2-10.e5.

2. Kolbel T, Carpenter SW, Lohrenz C, Tsilimparis N, Larena-Avellaneda A, Debus ES. Addressing persistent false lumen flow in chronic aortic dissection: the Knickerbocker technique. J Endovasc Ther. 2014;21:117-22.

3. Lombardi JV, Hughes GC, Appoo JJ, Bavaria JE, Beck AW, Cambria RP, et al. Society for Vascular Surgery (SVS) and Society of Thoracic Surgeons (STS) reporting standards for type B aortic dissections. Ann Thorac Surg. 2020;109:959-81.

4. Kilic A, Sultan IS, Arnaoutakis GJ, Higgins RS, Kilic A. Assessment of thoracic endografting operative mortality risk score: development and validation in 2,000 patients. Ann Thorac Surg. 2015;100:860-7.

5. Sultan I, Siki MA, Bavaria JE, Dibble TR, Savino DC, Kilic A, et al. Predicting distal aortic remodeling after endovascular repair for chronic DeBakey III aortic dissection. Ann Thorac Surg. 2018;105:1691-6.

6. Arnaoutakis DJ, Khan TA, Scali ST, Neal D, Giles KA, Cooper MA, et al. Remodeling, reintervention, and survival after endovascular repair of chronic type B dissection. Ann Thorac Surg. September 20, 2020 [Epub ahead of print].

\section{Commentary: A new chapter in chronic type B aortic dissection: Balloon fracture fenestration and remodeling}

\author{
Edward D. Percy, MD, ${ }^{\mathrm{a}, \mathrm{b}}$ and Ashraf A. Sabe, $\mathrm{MD}^{\mathrm{a}}$
}

Thoracic endovascular aortic repair (TEVAR) has become the standard of care in suitable patients with complicated

\footnotetext{
From the ${ }^{\mathrm{a}}$ Division of Cardiac Surgery, Department of Surgery, Brigham and Women's Hospital, Harvard Medical School, Boston, Mass; and ${ }^{\mathrm{b} D i v i s i o n}$ of Cardiovascular Surgery, University of British Columbia, Vancouver, British Columbia, Canada.

Disclosures: The authors reported no conflicts of interest.

The Journal policy requires editors and reviewers to disclose conflicts of interest and to decline handling or reviewing manuscripts for which they may have a conflict of interest. The editors and reviewers of this article have no conflicts of interest.

Received for publication Oct 8, 2020; revisions received Oct 8, 2020; accepted for publication Oct 9, 2020; available ahead of print Oct 17, 2020.

Address for reprints: Ashraf A. Sabe, MD, Division of Cardiac Surgery, Brigham and Women's Hospital, 75 Francis St, Boston, MA 02115 (E-mail: asabe@partners.org). J Thorac Cardiovasc Surg 2022;164:12-3 0022-5223/ $\$ 36.00$

Crown Copyright $(2020$ Published by Elsevier Inc. on behalf of The American Association for Thoracic Surgery

https://doi.org/10.1016/j.jtcvs.2020.10.036
}

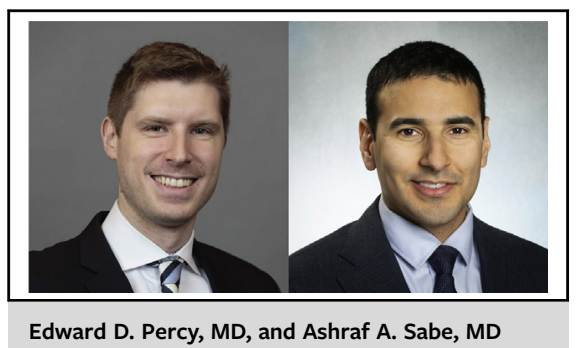

CENTRAL MESSAGE

Balloon fracture fenestration at

the time of thoracic

endovascular aortic repair of

chronic dissection appears to

be a safe and promising option

for promoting aortic

remodeling. 